\title{
Update: Product, Substance-Use, and Demographic Characteristics of Hospitalized Patients in a Nationwide Outbreak of E-cigarette, or Vaping, Product Use-Associated Lung Injury — United States, August 2019-January 2020
}

\begin{abstract}
Sascha Ellington, $\mathrm{PhD}^{1}$; Phillip P. Salvatore, $\mathrm{PhD}^{2,3}$; Jean Ko, $\mathrm{PhD}^{1}$; Melissa Danielson, MSPH${ }^{4}$; Lindsay Kim, $\mathrm{MD}^{5}$; Alissa Cyrus, MPH${ }^{6}$; Megan Wallace, PhD ${ }^{3,5}$; Amy Board, DrPH ${ }^{2,3}$; Vikram Krishnasamy, MD ${ }^{2}$; Brian A. King, PhD ${ }^{1}$; Dale Rose, PhD ${ }^{7}$; Christopher M. Jones, PharmD, DrPH${ }^{2}$; Lori A. Pollack, $\mathrm{MD}^{1}$; Lung Injury Response Epidemiology/Surveillance Task Force
\end{abstract}

On January 14, 2020, this report was posted as an MMWR Early Release on the MMWR website (https://www.cdc.gov/mmwr). CDC, the Food and Drug Administration (FDA), state and local health departments, and public health and clinical stakeholders continue to investigate a nationwide outbreak of e-cigarette, or vaping, product use-associated lung injury (EVALI) (1). EVALI patients in Illinois, Utah, and Wisconsin acquired tetrahydrocannabinol (THC)-containing products primarily from informal sources $(2,3)$. This report updates demographic characteristics and self-reported sources of THC- and nicotinecontaining e-cigarette, or vaping, products derived from EVALI patient data reported to CDC by state health departments. As of January 7, 2020, among 1,979 (76\%) patients with available data on substance use, a total of 1,620 (82\%) reported using any THC-containing products, including 665 (34\%) who reported exclusive THC-containing product use. Use of any nicotine-containing products was reported by 1,128 (57\%) patients, including 264 (13\%) who reported exclusive nicotine-containing product use. Among 809 (50\%) patients reporting data on the source of THC-containing products, $131(16 \%)$ reported acquiring their products from only commercial sources (i.e., recreational dispensaries, medical dispensaries, or both; vape or smoke shops; stores; and pop-up shops), 627 (78\%) from only informal sources (i.e., friends, family, in-person or online dealers, or other sources), and 51 (6\%) from both types of sources. Among 613 (54\%) EVALI patients reporting nicotine-containing product use with available data on product source, 421 (69\%) reported acquiring their products from only commercial sources, 103 (17\%) from only informal sources, and 89 (15\%) from both types of sources. Adolescents aged 13-17 years were more likely to acquire both THC- and nicotine-containing products from informal sources than were persons in older age groups. The high prevalence of acquisition of THC-containing products from informal sources by EVALI patients reinforces CDC's recommendation to not use e-cigarette, or vaping, products that contain THC, especially those acquired from informal sources. Although acquisition of nicotine-containing products through informal sources was not common overall, it was common among persons aged $<18$ years. While the investigation continues, $\mathrm{CDC}$ recommends that the best way for persons to ensure that they are not at risk is to consider refraining from the use of all e-cigarette, or vaping, products.

This report updates patient demographic characteristics, self-reported substance use, and e-cigarette, or vaping, product sources reported to CDC as of January 7, 2020. States and jurisdictions voluntarily report data on confirmed and probable hospitalized or deceased EVALI patients to CDC weekly using established case definitions* and data collection tools. ${ }^{\dagger}$ Data on substance use and product source were collected from EVALI patients or their proxies (e.g., family members) via standard interview. Commercial product sources were defined as recreational or medical dispensaries, vape or smoke shops, stores, and pop-up shops. Informal sources were defined as friends, family, in-person or online dealers, or other sources. Severe clinical course was defined as hospital stay of $\geq 10$ days; admission to an intensive care unit; requirement for endotracheal intubation, continuous positive airway pressure, or bilevel positive airway pressure; or death. All analyses were conducted using R software (version 3.6; R Foundation for Statistical Computing). The association of age group and product source was tested using Fisher's exact test, with p-values $<0.05$ considered statistically significant.

As of January 7, 2020, among 1,979 (76\%) patients with substance use data available, 1,620 (82\%) reported using any THC-containing e-cigarette, or vaping, products, and 665 (34\%) (i.e., $41 \%$ of patients reporting any THC-containing product use) reported exclusive use of these products (Table). Among patients reporting any THC-containing product use, $865(53 \%)$ had data on frequency of use; $641(74 \%)$ reported daily use, and $122(14 \%)$ reported using these products a few times per week. Among EVALI patients reporting any THCcontaining product use, 809 (50\%) reported product source,

\footnotetext{
*https://www.cdc.gov/tobacco/basic_information/e-cigarettes/assets/2019-LungInjury-Surveillance-Case-Definition-508.pdf.

$\dagger$ https://www.cdc.gov/tobacco/basic_information/e-cigarettes/severe-lungdisease/healthcare-providers/pdfs/National-Case-Report-Form-v01.pdf.
} 
TABLE. Demographic characteristics, substances used, and product sources among hospitalized* cases of e-cigarette, or vaping, product use-associated lung injury (EVALI) reported to CDC — United States, August 2019-January $2020^{\dagger}$

\begin{tabular}{|c|c|c|c|c|c|}
\hline \multirow[b]{2}{*}{ Characteristic } & \multicolumn{4}{|c|}{$\begin{array}{l}\text { Substance used } \\
\text { No./Total no. (\%) }\end{array}$} & \multirow[b]{2}{*}{$\begin{array}{l}\text { All cases } \\
(\mathrm{N}=2,602)\end{array}$} \\
\hline & $\begin{array}{c}\text { Any THC } \\
(\mathrm{N}=1,620)\end{array}$ & $\begin{array}{c}\text { Exclusive THC }{ }^{\S} \\
(\mathrm{N}=665)\end{array}$ & $\begin{array}{l}\text { Any nicotine } \\
(N=1,128)\end{array}$ & $\begin{array}{l}\text { Exclusive nicotine } \\
\quad(\mathrm{N}=264)\end{array}$ & \\
\hline \multicolumn{6}{|l|}{ Sex } \\
\hline Male & $1,116 / 1,613(69)$ & $447 / 662(68)$ & $759 / 1,124(68)$ & $154 / 264(58)$ & $1,658 / 2,486(67)$ \\
\hline Female & $497 / 1,613(31)$ & $215 / 662(32)$ & $365 / 1,124(32)$ & $110 / 264(42)$ & $828 / 2,486(33)$ \\
\hline \multicolumn{6}{|l|}{ Age group (yrs) } \\
\hline $13-17$ & $272 / 1,615(17)$ & $93 / 663(14)$ & $204 / 1,125$ (18) & $32 / 264(12)$ & $383 / 2,497(15)$ \\
\hline $18-24$ & $630 / 1,615(39)$ & $214 / 663(32)$ & $481 / 1,125(43)$ & $87 / 264(33)$ & $931 / 2,497$ (37) \\
\hline $25-34$ & $387 / 1,615(24)$ & $180 / 663(27)$ & $239 / 1,125(21)$ & $62 / 264(23)$ & $605 / 2,497(24)$ \\
\hline $35-44$ & $200 / 1,615(12)$ & $98 / 663(15)$ & $115 / 1,125(10)$ & $35 / 264(13)$ & $322 / 2,497(13)$ \\
\hline $45-64$ & $110 / 1,615(7)$ & $65 / 663(10)$ & $68 / 1,125(6)$ & $34 / 264(13)$ & $213 / 2,497(9)$ \\
\hline $65-85$ & $16 / 1,615(1)$ & $13 / 663(2)$ & $18 / 1,125(2)$ & $14 / 264(5)$ & $43 / 2,497$ (2) \\
\hline \multicolumn{6}{|l|}{ Race/Ethnicity** } \\
\hline White & $969 / 1,293(75)$ & $362 / 503(72)$ & $744 / 940(79)$ & $175 / 216(81)$ & $1,333 / 1,768(75)$ \\
\hline Black & $43 / 1,293(3)$ & $16 / 503(3)$ & $34 / 940(4)$ & $11 / 216(5)$ & $64 / 1,768(4)$ \\
\hline Hispanic & $219 / 1,293(17)$ & $110 / 503(22)$ & $104 / 940(11)$ & $18 / 216(8)$ & $281 / 1,768(16)$ \\
\hline Other & $62 / 1,293(5)$ & $15 / 503(3)$ & $58 / 940(6)$ & $12 / 216(6)$ & $90 / 1,768(5)$ \\
\hline \multicolumn{6}{|l|}{ Clinical course } \\
\hline Severe & $538 / 1,600(34)$ & $211 / 649(33)$ & $409 / 1,122(36)$ & $106 / 262(40)$ & $810 / 2,533(32)$ \\
\hline Not severe & $1,062 / 1,600(66)$ & $438 / 649(67)$ & $713 / 1,122(64)$ & $156 / 262(60)$ & $1,723 / 2,533(68)$ \\
\hline \multicolumn{6}{|l|}{ Outcome } \\
\hline Died & 28/1,493 (2) & $16 / 597(3)$ & $26 / 1,060(2)$ & $16 / 244(7)$ & $57 / 2,355(2)$ \\
\hline Survived & $1,465 / 1,493(98)$ & $581 / 597(97)$ & $1,034 / 1,060(98)$ & $228 / 244(93)$ & $2,298 / 2,355(98)$ \\
\hline \multicolumn{6}{|c|}{ E-cigarette, or vaping, substances reported ${ }^{t \dagger}$} \\
\hline Any THC & $1,620 / 1,620(100)$ & $665 / 665(100)$ & $811 / 1,128(72)$ & $\mathrm{N} / \mathrm{A}$ & $1,620 / 1,979(82)$ \\
\hline Any nicotine & $811 / 1,620(50)$ & N/A & $1,128 / 1,128(100)$ & $264 / 264(100)$ & $1,128 / 1,979(57)$ \\
\hline Any CBD & $251 / 1,620(15)$ & N/A & $154 / 1,128(14)$ & $\mathrm{N} / \mathrm{A}$ & $308 / 1,979(16)$ \\
\hline Any other substances $\S^{\S}$ & $115 / 1,620(7)$ & $\mathrm{N} / \mathrm{A}$ & $111 / 1,128(10)$ & $\mathrm{N} / \mathrm{A}$ & $158 / 1,979(8)$ \\
\hline \multicolumn{6}{|l|}{ THC use frequency } \\
\hline Daily & $641 / 865(74)$ & $225 / 294(77)$ & $331 / 468(71)$ & N/A & $641 / 865(74)$ \\
\hline A few times per week & $122 / 865(14)$ & 48/294 (16) & $61 / 468(13)$ & N/A & $122 / 865(14)$ \\
\hline A few times per month & $49 / 865(6)$ & $5 / 294(2)$ & $41 / 468(9)$ & $\mathrm{N} / \mathrm{A}$ & $49 / 865(6)$ \\
\hline Monthly or less & $53 / 865(6)$ & $16 / 294(5)$ & $35 / 468(7)$ & $\mathrm{N} / \mathrm{A}$ & $53 / 865(6)$ \\
\hline \multicolumn{6}{|l|}{ Nicotine use frequency } \\
\hline Daily & $407 / 481(85)$ & N/A & $580 / 681(85)$ & $135 / 160(84)$ & $580 / 681(85)$ \\
\hline A few times per week & $39 / 481(8)$ & N/A & $55 / 681(8)$ & $14 / 160(9)$ & $55 / 681(8)$ \\
\hline A few times per month & $17 / 481(4)$ & $\mathrm{N} / \mathrm{A}$ & $22 / 681(3)$ & $5 / 160(3)$ & $22 / 681(3)$ \\
\hline Monthly or less & $18 / 481(4)$ & $\mathrm{N} / \mathrm{A}$ & $24 / 681(4)$ & $6 / 160(4)$ & $24 / 681$ (4) \\
\hline
\end{tabular}

See table footnotes on the next page.

including 131 (16\%) who reported acquiring products from only commercial sources, 627 (78\%) from only informal sources, and $51(6 \%)$ from both sources. The most common sources reported for THC-containing products were family members or friends (38\%), followed by dealers (31\%), and other sources (23\%). Medical dispensaries were reported as a source for THC-containing products by $3 \%$ of EVALI patients and recreational dispensaries by $8 \%$ of EVALI patients.

Overall, 1,128 (57\%) patients reported using any nicotinecontaining products, and 264 (13\%) (i.e., 23\% of patients reporting any nicotine-containing product use) reported exclusive use of these products. Among 681 (60\%) patients with data available on frequency of nicotine-containing product use, $580(85 \%)$ reported daily use, with a similar percentage among exclusive (84\%) users. Among EVALI patients reporting use of any nicotine-containing product, $613(54 \%)$ reported product source, including 421 (69\%) who reported acquiring products from only commercial sources, 103 (17\%) from only informal sources, and 89 (15\%) from both sources. Among EVALI patients reporting use of any nicotine-containing products, the most commonly reported sources for nicotine-containing products were vape or smoke shops (48\%), stores (43\%), and family members or friends (15\%).

Younger age was significantly associated with acquiring THC-containing and nicotine-containing products through informal sources (Figure 1). Among EVALI patients reporting use of any THC-containing products, 122 of 130 (94\%) of those aged 13-17 years acquired products through only informal sources, compared with 42 of $68(62 \%)$ of those aged 45-77 years $(\mathrm{p}<0.001)$. Among EVALI patients reporting 
TABLE. (Continued) Demographic characteristics, substances used, and product sources among hospitalized* cases of e-cigarette, or vaping, product use-associated lung injury (EVALI) reported to CDC - United States, August 2019-January 2020 ${ }^{\dagger}$

Substance used

No./Total no. (\%)

\begin{tabular}{|c|c|c|c|c|c|}
\hline Characteristic & $\begin{array}{c}\text { Any THC } \\
(\mathrm{N}=1,620)\end{array}$ & $\begin{array}{l}\text { Exclusive THC } \S \\
\quad(\mathrm{N}=665)\end{array}$ & $\begin{array}{l}\text { Any nicotine } \\
(\mathrm{N}=1,128)\end{array}$ & $\begin{array}{l}\text { Exclusive nicotine } \\
\qquad(\mathrm{N}=264)\end{array}$ & $\begin{array}{c}\text { All cases } \\
(\mathrm{N}=2,602)\end{array}$ \\
\hline \multicolumn{6}{|l|}{ THC source } \\
\hline Pop-up shop & 20/783 (3) & $9 / 277(3)$ & $6 / 423(1)$ & $\mathrm{N} / \mathrm{A}$ & $20 / 783(3)$ \\
\hline Recreational dispensary & $63 / 783(8)$ & $26 / 277(9)$ & $28 / 423(7)$ & $\mathrm{N} / \mathrm{A}$ & $63 / 783(8)$ \\
\hline Medical dispensary & $27 / 783(3)$ & $10 / 277(4)$ & $14 / 423(3)$ & $\mathrm{N} / \mathrm{A}$ & $27 / 783(3)$ \\
\hline Vape or smoke shop & $44 / 783(6)$ & $15 / 277(5)$ & $23 / 423(5)$ & $\mathrm{N} / \mathrm{A}$ & $44 / 783(6)$ \\
\hline Store & $15 / 783(2)$ & $4 / 277(1)$ & $10 / 423(2)$ & $\mathrm{N} / \mathrm{A}$ & $15 / 783(2)$ \\
\hline Family or friend ${ }^{* * *}$ & $294 / 783(38)$ & $99 / 277(36)$ & $174 / 423(41)$ & $\mathrm{N} / \mathrm{A}$ & $294 / 783(38)$ \\
\hline Dealer*** & 240/783 (31) & $82 / 277(30)$ & $140 / 423(33)$ & $\mathrm{N} / \mathrm{A}$ & $240 / 783(31)$ \\
\hline Online ${ }^{* * *}$ & $43 / 783(5)$ & 19/277 (7) & $19 / 423(4)$ & $\mathrm{N} / \mathrm{A}$ & $43 / 783(5)$ \\
\hline Other ${ }^{* * *}$ & $177 / 783(23)$ & $62 / 277(22)$ & $86 / 423(20)$ & $\mathrm{N} / \mathrm{A}$ & $177 / 783(23)$ \\
\hline Only commercial sources & $131 / 809(16)$ & $47 / 285(16)$ & $61 / 436(14)$ & N/A & $131 / 809(16)$ \\
\hline Only informal sources & $627 / 809(78)$ & $216 / 285(76)$ & $352 / 436(81)$ & $\mathrm{N} / \mathrm{A}$ & $627 / 809(78)$ \\
\hline Commercial and informal & $51 / 809(6)$ & $22 / 285(8)$ & $23 / 436(5)$ & $\mathrm{N} / \mathrm{A}$ & $51 / 809(6)$ \\
\hline \multicolumn{6}{|l|}{ Nicotine source } \\
\hline Pop-up Shop ${ }^{91}$ & $2 / 430(0)$ & $\mathrm{N} / \mathrm{A}$ & $2 / 595(0)$ & 0/131 (0) & $2 / 595(0)$ \\
\hline Recreational dispensary & $7 / 430(2)$ & $N / A$ & $7 / 595(1)$ & $0 / 131(0)$ & $7 / 595(1)$ \\
\hline Vape or smoke shop 19 & $197 / 430(46)$ & $\mathrm{N} / \mathrm{A}$ & $287 / 595(48)$ & $67 / 131(51)$ & $287 / 595(48)$ \\
\hline Store & $188 / 430(44)$ & N/A & $253 / 595(43)$ & $54 / 131(41)$ & $253 / 595(43)$ \\
\hline Family or friend*** & $76 / 430(18)$ & N/A & $91 / 595(15)$ & 13/131 (10) & $91 / 595(15)$ \\
\hline Dealer*** & $15 / 430(3)$ & $\mathrm{N} / \mathrm{A}$ & $15 / 595(3)$ & $0 / 131(0)$ & $15 / 595(3)$ \\
\hline Online ${ }^{* * *}$ & $40 / 430(9)$ & N/A & $54 / 595(9)$ & $10 / 131(8)$ & $54 / 595$ (9) \\
\hline Other*** & $42 / 430(10)$ & $\mathrm{N} / \mathrm{A}$ & $57 / 595(10)$ & $12 / 131(9)$ & $57 / 595(10)$ \\
\hline Only commercial sources & 289/442 (65) & $\mathrm{N} / \mathrm{A}$ & $421 / 613(69)$ & 105/136 (77) & $421 / 613(69)$ \\
\hline Only informal sources & $77 / 442(17)$ & $\mathrm{N} / \mathrm{A}$ & $103 / 613(17)$ & 23/136 (17) & $103 / 613(17)$ \\
\hline Commercial and informal & $76 / 442(17)$ & N/A & $89 / 613(15)$ & $8 / 136(6)$ & $89 / 613(15)$ \\
\hline
\end{tabular}

Abbreviations: $\mathrm{CBD}=$ cannabidiol; $\mathrm{N} / \mathrm{A}=$ not applicable; $\mathrm{THC}=$ tetrahydrocannabinol.

* Includes all hospitalized EVALI patients and EVALI-associated deaths $(n=57)$ regardless of hospitalization status.

† For cases reported as of January 7, 2020.

$\S$ Exclusive THC use defined as anyone who reported THC and no other substances (e.g., nicotine, CBD, synthetics, flavors, or other).

I Exclusive nicotine use defined as anyone who reported nicotine and no other substances (e.g., THC, CBD, synthetics, flavors, or other).

** Whites, blacks, and others were all non-Hispanic. Hispanic persons could be of any race.

${ }^{+\dagger}$ In the 3 months preceding symptom onset.

$\S \S$ Includes synthetic cannabinoids and flavors.

กศ Commercial source.

*** Informal source.

use of any nicotine-containing products, 46 of 109 (42\%) of those aged 13-17 years acquired products through only informal sources, compared with five of $43(12 \%)$ of those aged $45-75$ years $(\mathrm{p}<0.001)$.

The percentage of EVALI patients in each state acquiring THC-containing products from informal sources varied (Figure 2). Alaska, Hawaii, Idaho, Iowa, Mississippi, Montana, Oklahoma, Rhode Island, South Dakota, and Vermont had the highest percentages of patients acquiring THC-containing products from informal sources $(50-100 \%)$. The percentage of EVALI patients acquiring nicotine-containing products from informal sources also varied by state, with Nevada having the highest percentage (57\%).

\section{Discussion}

Differences in product sources for THC- and nicotinecontaining products were identified: obtaining products from only informal sources was substantially more common for THC- than for nicotine-containing products, whereas obtaining products only from commercial sources was much more common for nicotine- than for THC-containing products. These findings are consistent with previous reports on EVALI cases from Illinois, Utah, and Wisconsin, which also found that most THC-containing products were acquired from informal sources, whereas most nicotine-containing products were acquired from commercial sources $(2,3)$.

The reported use of THC-containing products from informal sources by most EVALI patients is important because vitamin $\mathrm{E}$ acetate has been detected in products obtained from these sources and has been associated with EVALI. As part of the investigation into the nationwide outbreak, FDA has conducted testing on products obtained from 73 EVALI patients; $79 \%$ of them had at least one product test positive for THC; among those, $78 \%$ had at least one product test 
FIGURE 1. Reported product sources, $*,+, \S$ by age group,,${ }^{1, * *}$ among hospitalized e-cigarette, or vaping, product use-associated lung injury (EVALI) patients - United States, August 2019-January 2020
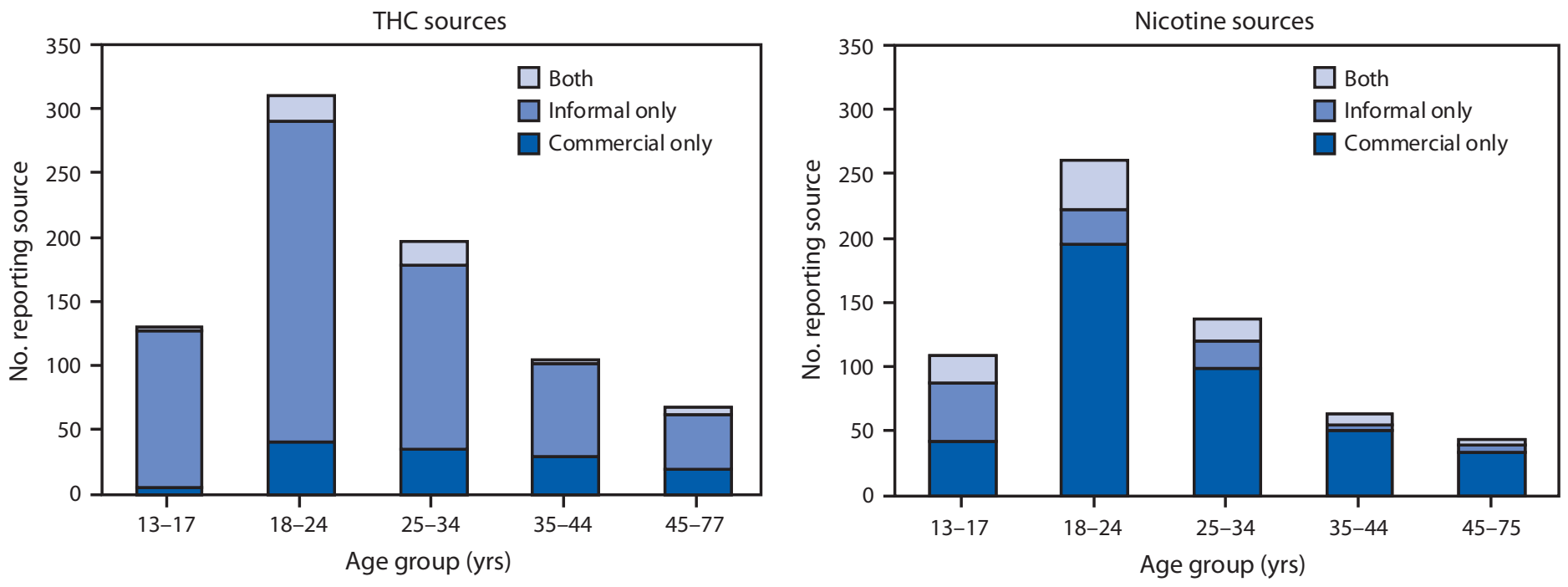

Abbreviation: $\mathrm{THC}=$ tetrahydrocannabinol.

* Among 809 EVALI patients reporting use of THC-containing products and for whom data on product source (commercial or informal) and age were available.

${ }^{\dagger}$ Among 613 EVALI patients reporting use of nicotine-containing products and for whom data on product source (commercial or informal) and age were available.

$\S$ Informal sources are defined as friends, family, in-person or online dealers, or other sources.

I $\mathrm{P}<0.001$ for comparison of proportions reporting THC source by age.

** $\mathrm{P}<0.001$ for comparison of proportions reporting nicotine source by age.

positive for vitamin $\mathrm{E}$ acetate. ${ }^{\S} \mathrm{A}$ recent case-control study found vitamin $\mathrm{E}$ acetate in the bronchoalveolar lavage fluid of $94 \%$ of 51 EVALI patients and in none of 99 healthy controls in the comparator group (4). In addition, an analysis of THC-containing products seized by law enforcement in Minnesota found no vitamin $\mathrm{E}$ acetate in 10 products seized in 2018 , and $100 \%$ of 20 products seized in 2019 contained vitamin $\mathrm{E}$ acetate (5).

Although most EVALI cases have been associated with use of informally sourced THC-containing products, $16 \%$ of patients reporting use of THC-containing products reported acquiring them only from commercial sources. Even in states where marijuana has been legalized for recreational use by adults, 9 it might be difficult to determine whether a source is licensed through the state. For example, in California, the Bureau of Cannabis Control seized nearly 10,000 illegal vape pens from unlicensed retailers during December 10-12, 2019.** The high prevalence of informally sourced THC-containing products among EVALI patients reinforces current recommendations to not use THC-containing e-cigarette, or vaping, products, particularly those acquired from informal sources.

\footnotetext{
$\$$ https://www.fda.gov/news-events/public-health-focus/

lung-illnesses-associated-use-vaping-products.

9 https://teens.drugabuse.gov/blog/post/how-legal-marijuana.

** https://bcc.ca.gov/about_us/documents/media_20191213_2.pdf.
}

The findings in this report are subject to at least four limitations. First, data on substances used and product sources were reported by patients or their proxies and might be subject to recall or social desirability bias. A recent study found that among 11 EVALI patients who reported no use of THCcontaining e-cigarette, or vaping, products, nine had THC or its metabolites detected in bronchoalveolar lavage fluid (4). Second, data on e-cigarette, or vaping, product substances used were missing for $24 \%$ of patients overall, and product source was missing for $50 \%$ of THC-containing product users and $46 \%$ of nicotine-containing product users. Therefore, conclusions derived from these data might not be generalizable to all EVALI patients. Third, patients might not know the contents of their e-cigarette, or vaping, products, which might lead to misclassification of substance use. Finally, EVALI is a diagnosis of exclusion with an intentionally sensitive case definition, and it is possible that cases caused by other etiologies could be misattributed to EVALI.

Vitamin $\mathrm{E}$ acetate has been identified as an additive in THC-containing e-cigarette, or vaping, products used by EVALI patients, and laboratory studies have demonstrated that it is associated with lung injury ${ }^{\dagger \dagger}(4-6)$. However, additional research is needed because there might be more than

\footnotetext{
$\dagger_{\dagger}$ https://www.fda.gov/news-events/public-health-focus/ lung-illnesses-associated-use-vaping-products.
} 
FIGURE 2. Percentage of hospitalized e-cigarette, or vaping, product use-associated lung injury (EVALI) patients reporting informal product sources, ${ }^{*}$ by state - United States, August 2019January 2020

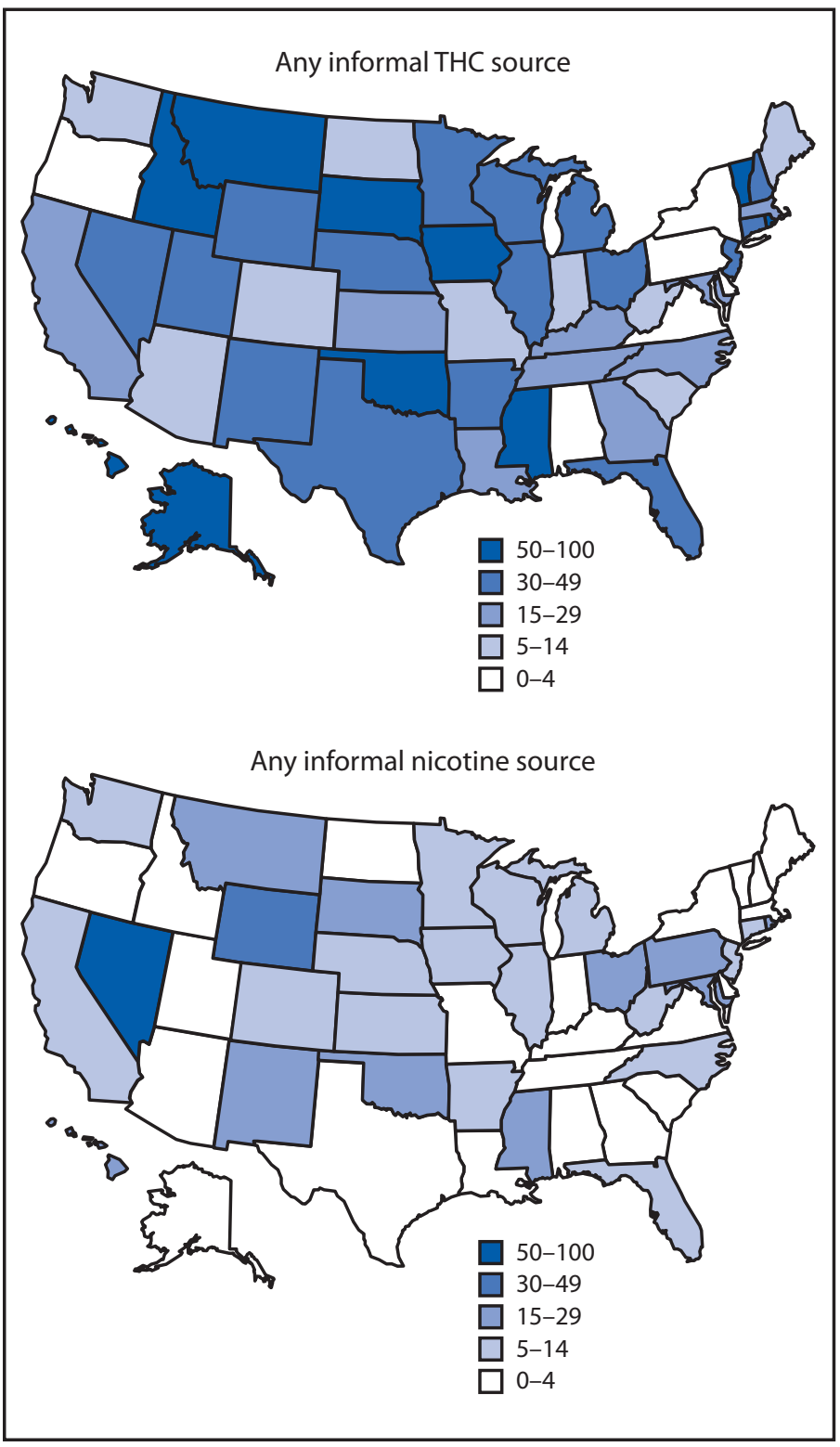

Abbreviation: $\mathrm{THC}=$ tetrahydrocannabinol.

* Informal sources are defined as friends, family, in-person or online dealers, or other sources.

one cause of this outbreak, and some patients report using only nicotine-containing products. Therefore, while the investigation continues, CDC recommends that the best way for persons to ensure that they are not at risk is to consider refraining from the use of all e-cigarette, or vaping, products. Adults using e-cigarette, or vaping, products to quit smoking should not return to smoking cigarettes; they should weigh

\section{Summary}

What is already known about this topic?

E-cigarette, or vaping, product use-associated lung injury (EVALI) patients in Illinois, Utah, and Wisconsin acquired tetrahydrocannabinol (THC)-containing products primarily from informal sources.

What is added by this report?

Nationwide, most EVALI patients with data on product source reported acquiring THC-containing products from only informal sources, whereas most nicotine-containing products were acquired from commercial sources. EVALI patients aged 13-17 years were more likely to acquire both THC- and nicotinecontaining products from informal sources than were adults.

What are the implications for public health practice?

While the investigation continues, CDC recommends that the best way for persons to ensure that they are not at risk is to consider refraining from the use of all e-cigarette, or vaping, products.

all risks and benefits and consider using FDA-approved cessation medications. ${ }^{\mathbb{S}}$ Adults who continue to use e-cigarette, or vaping, products should carefully monitor themselves for symptoms and see a health care provider immediately if they develop symptoms similar to those reported in this outbreak (7). Irrespective of the ongoing investigation, e-cigarette, or vaping, products should never be used by youths, young adults, or pregnant women.

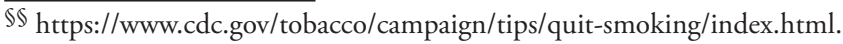

\section{Acknowledgments}

Sarah Khalidi, Sondra Reese, Alabama Department of Public Health; Joseph B. McLaughlin, Eric Q. Mooring, Alaska Division of Public Health; Emily M. Carlson, Tiana Galindo, Arizona Department of Health Services; Appathurai Balamurugan, Allison James, Brandy Sutphin, Arkansas Department of Health; California Department of Public Health EVALI Investigation Team; Elyse Contreras, Richard Holdman, Colorado Department of Public Health and Environment; Sydney Jones, Jaime Krasnitski, Connecticut Department of Public Health; Amanda Bundek, Caroline Judd, Delaware Department of Health and Social Services; Adrienne Sherman, Kenan Zamore, District of Columbia Department of Health; Heather Rubino, Thomas Troelstrup, Florida Department of Health; Georgia Department of Public Health; Hawaii Department of Health; Eileen M. Dunne, Scott C. Hutton, Kathryn A. Turner, Idaho Division of Public Health; Gerry C. Fajardo, Isaac Ghinai, Illinois Department of Public Health; Charles R. Clark, Indiana State Department of Health; Chris Galeazzi, Tyra Goss, Nicholas Kalas, Scott Seltrecht, Iowa Department of Public Health; Justin Blanding, Amie Cook, Kansas Department of Health and Environment; Kentucky Department for Public Health; Julie Hand, Theresa Sokol, Louisiana Department of Health; Maine Center for Disease Control and Prevention; Kenneth A. Feder, Clifford S. Mitchell, 
Maryland Department of Health; Leslie Fowle, Caroline Krawczyk, Massachusetts Department of Public Health; Rita Seith, Eden V. Wells, Michigan Department of Health and Human Services; Stacy Holzbauer, Terra Wiens, Minnesota Department of Health; Paul Byers, Kathryn Taylor, Mississippi State Department of Health; Valerie Howard, George Turabelidze, Missouri Department of Health and Senior Services; Laura L. Williamson, Montana Department of Public Health and Human Services; Matthew Donahue, Tom Safranek, Nebraska Department of Health and Human Services; Ashleigh Faulstich, Victoria LeGarde, Melissa Peek-Bullock, Nevada Department of Health and Human Services; Pascal Kalin, Darlene Morse, New Hampshire Department of Health and Human Services; Lisa McHugh, Stephen Perez, New Jersey Department of Health; Alex Gallegos, Joseph T. Hicks, New Mexico Department of Health; Kristen Navarette, Monica Nordstorm, New York State Department of Health; Molly N. Hoffman, Kendall B. Knuth, Dana Dandeneau, North Carolina Division of Public Health; Tracy Miller, Kodi Pinks, North Dakota Department of Health; Courtney Dewart, Kirtana Ramadugu, Ohio Department of Health; Claire B. Nguyen, Tracy Wendling, Oklahoma State Department of Health; Laurel Boyd, Amanda Faulkner, Tasha Poissant, Steve Rekant, Oregon Health Authority; Pennsylvania Department of Health; Ada Lily Ramírez Osorio, Departamento de Salud de Puerto Rico; Ailis Clyne, Morgan Orr, James Rajotte, Rhode Island Department of Health; Sharon Biggers, Virginie Daguise, Daniel Kilpatrick, South Carolina Department of Health \& Environmental Control; Joshua L. Clayton, Kipp Stahl, Jonathan Steinberg, South Dakota Department of Health; Julie Shaffner, Kelly Squires, Tennessee Department of Health; DeLayna Goulding, Ketki Patel, Varun Shetty, Haylea Stuteville, Texas Department of State Health Services; Esther M. Ellis, U.S. Virgin Islands Department of Health; Jordan Green, Keegan McCaffery, Utah Department of Health; Vermont Department of Health; Jonathan Falk, Lilian Peake, Virginia Department of Health; Trevor Christensen, Melanie Payne, Washington State Department of Health; Shannon McBee, Christy Reed, West Virginia Department of Health and Human Resources; Jonathan Meiman, Ian Pray, Wisconsin Department of Health Services; Melissa Taylor, Wyoming Department of Health.

\section{Lung Injury Response Epidemiology/Surveillance Task Force}

Amena Abbas, National Center for Chronic Disease Prevention and Health Promotion, CDC; Adebola Adebayo, National Center for Injury Prevention and Control, CDC; Sukhshant Atti, Agency For Toxic Substances and Disease Registry, CDC; Elizabeth Carter, National Center for Environmental Health, CDC; Gyan Chandra, National Center for Chronic Disease Prevention and Health Promotion, CDC; Lindsay Eckhaus, National Center for Chronic Disease Prevention and Health Promotion, CDC; Geroncio Fajardo, National Center for Emerging and Zoonotic Infectious Diseases, CDC; Sonal Goyal, National Center for Chronic Disease Prevention and Health Promotion, CDC; Benjamin Hallowell, National Center for Immunization and Respiratory Diseases, CDC; Janet Hamilton, Council of State and Territorial Epidemiologists; Mia Israel, Council of State and Territorial Epidemiologists; Zheng Li, Agency For Toxic
Substances and Disease Registry, CDC; Caitlin Loretan, National Center for Immunization and Respiratory Diseases, CDC; Ruth Lynfield, Minnesota Department of Health; Paul Melstrom, National Center for Chronic Disease Prevention and Health Promotion, CDC; Mary Pomeroy, National Center for Emerging and Zoonotic Infectious Diseases, CDC; Caroline Schrodt, National Center for Emerging and Zoonotic Infectious Diseases, CDC; Stephen Soroka, National Center for Emerging and Zoonotic Infectious Diseases, CDC; Kimberly Thomas, Center for Surveillance, Epidemiology, and Laboratory Services, CDC; Bailey M. Wallace, National Center on Birth Defects and Developmental Disabilities, CDC.

Corresponding author: Sascha Ellington, SEllington@cdc.gov.

${ }^{1}$ National Center for Chronic Disease Prevention and Health Promotion, CDC; ${ }^{2}$ National Center for Injury Prevention and Control, CDC; ${ }^{3}$ Epidemic Intelligence Service, CDC; ${ }^{4}$ National Center on Birth Defects and Developmental Disabilities, CDC; ${ }^{5}$ National Center for Immunization and Respiratory Diseases, CDC; ${ }^{6}$ Office of Minority Health and Health Equity, CDC; ${ }^{7}$ National Center for Emerging and Zoonotic Infectious Diseases, CDC.

All authors have completed and submitted the International Committee of Medical Journal Editors form for disclosure of potential conflicts of interest. No potential conflicts of interest were disclosed.

\section{References}

1. Moritz ED, Zapata LB, Lekiachvili A, et al.; Lung Injury Response Epidemiology/Surveillance Group. Update: characteristics of patients in a national outbreak of e-cigarette, or vaping, product use-associated lung injuries-United States, October 2019. MMWR Morb Mortal Wkly Rep 2019;68:985-9. https://doi.org/10.15585/mmwr.mm6843e1

2. Ghinai I, Pray IW, Navon L, et al. E-cigarette product use, or vaping, among persons with associated lung injury-Illinois and Wisconsin, April-September 2019. MMWR Morb Mortal Wkly Rep 2019;68:865-9. https://doi.org/10.15585/mmwr.mm6839e2

3. Lewis N, McCaffrey K, Sage K, et al. E-cigarette use, or vaping, practices and characteristics among persons with associated lung injury-Utah, April-October 2019. MMWR Morb Mortal Wkly Rep 2019;68:953-6. https://doi.org/10.15585/mmwr.mm6842e1

4. Blount BC, Karwowski MP, Shields PG, et al.; Lung Injury Response Laboratory Working Group. Vitamin E acetate in bronchoalveolar-lavage fluid associated with EVALI. N Engl J Med 2019;NEJMoa1916433. https://doi.org/10.1056/NEJMoa1916433

5. Taylor J, Wiens T, Peterson J, et al.; Lung Injury Response Task Force. Characteristics of e-cigarette, or vaping, products used by patients with associated lung injury and products seized by law enforcementMinnesota, 2018 and 2019. MMWR Morb Mortal Wkly Rep 2019;68:1096-100. https://doi.org/10.15585/mmwr.mm6847e1

6. Blount BC, Karwowski MP, Morel-Espinosa M, et al. Evaluation of bronchoalveolar lavage fluid from patients in an outbreak of e-cigarette, or vaping, product use-associated lung injury - 10 states, August-October 2019. MMWR Morb Mortal Wkly Rep 2019;68:1040-1. https://doi. org/10.15585/mmwr.mm6845e2

7. Evans ME, Twentyman E, Click ES, et al.; Lung Injury Response Clinical Task Force; Lung Injury Response Clinical Working Group. Update: interim guidance for health care professionals evaluating and caring for patients with suspected e-cigarette, or vaping, product use-associated lung injury and for reducing the risk for rehospitalization and death following hospital discharge-United States, December 2019. MMWR Morb Mortal Wkly Rep 2020;68:1189-94. https://doi.org/10.15585/mmwr. mm685152e2 